Neste artigo as autoras apresentamuma leitura do seminário IV de Lacan que enfoca, através da escansão de três tempos lógicas (Privação, Fnustração e Castração) , a transmissão da falta como eixo fundamental da constituiçãodosujeito.

Transmissão da falta; privação; frustração; castração

LACK'S TRANSMISSION FROM A VIEW OF LLACAN'S SEMINAR BOOK FOUR

This paper presents a view of the Iacan's Seminar Book Four fooused on the ladk's transmission as the main point of the subject constitution thraghat three logical maments: privation, frustrationand castration. Iack's transmission; privation; frustration; castration

\section{A TRANSMISSÃO DA FALTA, A PARTIR DA LEITURA DO SEMINÁRIO IV DE $\mathrm{LACAN}$}

\author{
Ilana Katz Z. Fragelli
}

Renata Petri
H.

seu quarto seminário, Lacan aborda a constituição do sujeito a partir de sua relação com o objeto. No entanto, tal abordagem é feita de um modo muito específico, uma vez que aquilo que o autor tratou como relação de objeto é, na verdade, a relação com a falta do objeto. É mesmo Lacan quem nos indica a presença dessa idéia na dbra de Freud.

A primeira estrutura do aparelho psíquico, formula Freud, é de um aparelho reflexo, constituído por neurônios regidos pela lógica de se manter livre de estímulos, descarregando as excitações recebidas pela via motora, ou simplesmente fugindo dos estímulos provenientes do mundo exterior. Essa inércia neurônica é interrompida por estimulações endógenas (fome ou sede: frutos de ausência de algo) que, ao criarem um estado de tensão, obrigam o organismo a realizar uma

Psicanalista, membro do setor de psicologia da DERDIC-PUC/SP, mestre no IP/USP.

- Psicanalista, doutoranda no IP/USP 
ação específica no mundo extemo, única altemativa para diminuir a intensidade produzida no interior do aparelho pelo estímulo recebido. O aumento do estímulo é associado à produção de desprazer e sua diminuição, conseqüentemente, produz a sensação de prazer no aparelho. Nas palavras de Freud (1895) : "Como já temos conhecimento de uma tendência da vida psíquica a evitar o desprazer, samos tentadbs a identificá-Ia com a tendência primária à inércid" (p. 33) .

Um "indivíduo prestativo"1, afirma Freud, realiza a ação específica no mundo externo para o pequeno humano desprovido dessa possibilidade. Se o bebê chora porque tem fome e o outro atende sua demanda oferecendo o leite, o bebê poderá, então, cancelar o estímulo endógeno. Essa é a experiência batizada por Freud de vivência de satisfação, uma experiência decisiva para a constituição do sujeito que está por vir (1895, p. 32) .

Já no texto do Projeto está claro que qualquer ação específica só terá sucesso, se for seguida de uma vivência de satisfação que elimine o estímulo intemo e, desse modo, faça marca no apareIho, conservando um traço do percebido. É muito importante frisar que se trata de traços relacionados àquilo que foi experimentado como satisfação. Isso quer dizer que, em termos freudianos, diante da experiência de saciedade da fome não se inscreve o seio camo dbjeto no aparelho. O dbjeto (da pulsão) sobre o qual Freud discorre não é uma coisa do mundo que se oferece à percepção, mas uma síntese, operada pela incidência da palavra, de representações dispersas que Freud denomina representações-dbjeto. Por exemplo, o que é investido não é o seio enquanto dbjeto que existe no mundo, mas a sua representação no aparelho, que não é a imagem e semelhança do peito. É a própria representação que é tomada como objeto.

Da próxima vez que a necessidade colocar o pequeno humano em estado de tensão, ele poderá recorrer a essa marca da memória para tentar restabelecer o apaziguamento relativo à satisfação. Freud (1895) explica: "Origina-se, através da vivência de satisfação, uma faci litação entre duas imagens recordativas e os neurônios nucleares que, no estadb de incitação, são capadbs" (p. 33) . Tal apaziguamento se produz como referência, uma vez que se relacicna ao registro da experiência, enão mais à vivência de satisfação propriamente dita. Freud ensina que aquilo que se apresentou como dbjeto para tal satisfação não será mais encontrado, estará para sempre perdido.

Nas palavras de Lacan: "Uma nostalgia liga o sujeito ao dbjeto perdidb, através da qual se exerce toob o esforço da luusca. Ella marca a redescoberta do signo de uma repetição impossível, já 
que, precisamente, este não é o mesmo dbjeto, não poderia sê-lo" (p. 13) .

No Seminário 4, Lacan distingue três formas de falta de dbjeto, au seja, três registros diferentes da falta, que se articulam para confeccionar o sujeito. São eles: a privação, a frustração e a castração. São três tempos lógicos distintos da transmissão da falta e cada tempo engldba e ressignifica o anterior, ampliandb as possibilicades de ciraulação disarsiva do sujeito.

\section{PRIVAÇÃO}

Há, num primeiro momento, uma relação supostamente dual entre a mãe e a criança. O bebê, sujeito da necessidade, grita frente à tensão orgânica causada pela fome. A mãe interpreta este grito como apelo, au seja, vê-se convocada pela criança a satisfazê-la e responde, oferecendb o dbjeto alimento, dbjeto da satisfação da necessidade, acompanhado de uma tessitura desejante.

É importante ressal tar que, para a mãe poder interpretar este chamado da criança, é preciso que ela se tome como não-toda. Deste modo, a mãe se apresenta como uma matriz simbólica para a criança, altemanob-se entre presença e ausência.

A falta, no registro da privação, incide de modos diferentes para a criança e para a mãe. A mãe se vê privada da criança como representante do abjeto de seu desejo, au seja, como dbjeto simbólico. Já a criança é privada da mãe, enquanto dojeto real da satisfação de sua necessidade (leite) . O agente da privação para ambas é o pai imaginário, ou seja, qualquer movimento que venha interferir e romper com o transitivismo característico desta relação inicial entre a mãe e a criança.

Este seria o primeiro desencontro inevitável entre o movimento desejante da mãe e a necessidade da criança que, em 1964, Lacan elabora assim: "Pois, depois de tudo, por que a cena primitiva é tão traumática? Por que ela é sempre muito cedo ou muito tarde? (... Trata-se, na experiência analítica, de partir do fato de que, se a cena primitiva é traumática, não é a empatia sexual que sustenta as modulações do analisável, mas um fato fictício" (p. 71) .

Ainda que tudo se cumpra, há um "fora do tempo", um (des) tempo que garante o desencontro necessário da mãe com a criança.

Há uma diferença importante a ser precisada: essa falta, quando incide no real, não está no sujeito. "A privação está no real, completamente fora do sujeito. Para que o sujeito apreenda a 
privação, é preciso inicialmente que ele simbolize o real" (Lacan, 195657, p. 55) . Lacan explica essa idéia através do exemplo da organização de uma biblioteca. Quando solicitamos ao bibliotecário um livro, ele pode nos responder, depois de proarrar em suas estantes, que tal dojeto não está no lugar e isso quer dizer que o livro não está disponível para ser retirado. Pode ser, porém, que o livro esteja colocado scbre a mesa do funcionário, no setor de "devolvidos" . O que essa cena nos mostra é que, apesar de o livro estar nabiblioteca, esta última está privada dele. O bibliotecário, sujeito à lei de organização da biblioteca, vive inteiramente no mundo simbólico. Para ele, o livro fora do lugar designado simbolicamente está invisível.

Será exatamente a simbolização do real que permitirá à mãe introduzir a criança na ordem simbólica e essa qperação será instituŕda a partir do tempo seguinte.

\section{FRUSTRAÇÃO}

Conforme descrevemos anteriormente, a partir do momento em que há incidência do chamado pai imaginário, que interrompe o ritmo da altemância entre a mãe e a criança, a primeira, que até então se apresentava como uma matriz simbólica, passa a se apresentar também como real. Ela aparece munida de grande potência à qual a criança se submete, numa dependência aterrorizadora. Lacan usa a figura da mãe insaciável para dar a dimensão da voracidade seu desejo.
Mas o que confere potência à mãe?

Os dbjetos que ela oferece à criança também sofrem uma mudança de estatuto e, em vez de objetos reais (leite) , que, sob a ótica da criança, lhe seriam previsivelmente entregues, a mãe passa a ser a possuidora de abjetos de dom simbólicas, que, por sua vez, estão sujeitos a uma outra lógica e assim podem ser oferecidas_ou não_à criança.

Os abjetos de dom são os objetos símbolo do amor, que ganham terreno quando o dbjeto da necessidade é tomado pela via simbólica, implicando aŕ, no eixo pulsional, toob circuito das trocas e, no espectro db significante, as possibilidades de substituição do abjeto propriamente dito.

Mas, para que essa qperação seja possível, o dbjeto deve ser primeiro anulado como referente da necessidade, uma vez que o dom é formulado como aquil lo que se dá pela mãe ao apelo da criança, e a criança só pode reivindicar aquilo que não está presente.

À criança resta, então, por causa de sua dependência radical dos objetos que a mãe oferece ou não, oferecer a si mesma como objeto da mãe. Isso acontece na tentativa da criança de conter o furor de satisfação da mãe e, assim, toma-se parte dessa economia psíquica, suportando em si um estatuto de objeto (em maior ou menor grau).

A criança, diz Lacan, se faz falo da mãe, na tentativa de garantir a oferta de dbjetos de satisfação. Este é um jogo de engoob, em que a criança dotura a primeira brecha que vislumbra porque lê que é a partir des- 
sa brecha, do que não há, do que é falta na mãe, que o agente da função materna se lança em direções nem sempre coincidentes às relativas à sua própria satisfação. Trata-se de uma questão de sobrevivência: afinal para a criança a presença da mãe está diretamente vinculada à sua satisfação. Identificandb-se ao falo, a criança restitui à mãe, mantendoa completa, ainda que ao preço de se manter alienada a ela.

É por esse caminho que se instala a dialética da frustração_au o paraíso do engodo _ articulada essencialmente em torno de três elementos: a mãe, a criança e o falo.

A partir do ingresso da criança na dialética da frustração, é importante ressaltar que, embora o dbjeto real não seja indiferente, não há necessidade alguma de ser específico. "Mesmo que não seja o seio da mãe, nempor isso ele perderá algo do valor de seu lugar na dialética sexual, de onde se origina a erotização da zona oral. Não é o objeto que desempenha, em seu interior, o papel essencial, mas o fato de que a atividade assumiu uma função erotizada no plano do desejo, o qual se ordena na ordem simbólica" (Iacan, p. 188) .

Para o fi iho, não importa qual é o alimento que a mãe oferece, mas a posição a partir da qual ela faz esta oferta. Eila pode al imentar a criança a partir de seu corpo, situada apenas no eixo da necessidade, sem veicular o amor; tanto quanto oferecer uma chupeta e satisfazer a criança, na dimensão do dom.

A operação que se dá nesse momento de transformação do objeto real em objeto de dom é fundamen- tal para introouzir a criança na ordem humana. Como já foi formulado, o dom se manifesta ao apelo, e "o apelo já é uma introoução, totalmente engajada na ordem simbólica, à palavra" (Lacan, 1956-57, p. 186) . É a partir dessa transformação que podemos escutar as demandas da criança, já como uma tentativa de veicular um desejo ainda incipiente e responder a elas com um símbolo do amor, como um reconhecimento desse desejo. Esse reconhecimento se veicula na língua, compalavras, uma vez que o que está em jogo não é a oferta de um dojeto determinado que possa destruir o desejo. Lacan (1956-57) enuncia que o dom-tipo é justamente o dom da palavra. 'Desde a origem, a criança se alimenta tanto de palavras quanto de pão, e perece por palavras" (p. 192).

Um quadro que não é raro se instalar nesse momento da constituição e que coloca às claras esse funcionamento é o que Lacan chamou de anorexia mental, que não é relativo ao não comer, mas ao comer nada, algo que só existe no plano simbólico. Através desse sintoma, a criança inverte sua relação com a mãe e a coloca na sua dependência. o sujeito submete o capricho da mãe onipotente à sua força, articulada ao "comer nada." O sujeito come nada para guardar vazio o espaço do desejo e não ser tomado pela via da necessidade. Assim, o dbjeto real (comida nada), escapa da trama da satisfação relativa ao vital e toma-se signo da exigência de amor. Há uma satisfação que responde ao vital_barriga cheia, mas isso é signo do dom, ou seja, nada em ter- 
mos de satisfação pulsional, uma vez que a satisfação que está em jogo pela via da frustração (aquela à qual o sujeito faz o apelo) advém da ordem decepcionante do simbólico.

"É no nível do objeto anulado como simbólico _ pela mãe _ que a criança põe em xeque a sua dependência, e precisamente alimentando-se de nada" (Lacan, 1956-57, p. 190) . E isso só é passível de ser engendrado, se a ordem simbólica já estiver operandb.

Neste ponto, vale fazer um parêntese para pensarmas em qual dimensão essa lógica pode ter nas relações intersubjetivas, na atualidade. Vivemos num tempo em que é muito comum vermos pais e educadores impotentes ante as demandas da criança, incapazes de ler que, quando a criança reivindica um dojeto da realidade, não é isso que ela deseja. Os adultas se engajam em satisfazê-la com a oferta de objetos reais, uma vez que tomam a falta como um vazio a ser preenchido em vez de como motor do funcionamento psíquico. É de fato característica do discurso social contemporâneo a veiculação da ilusão da completude e valorização do dbjeto por suas características reais de eficiência, velocidade, competência, preço etc. , e não pelo lugar que ocupa numa série intersubjetiva. Para a criança, ganhar uma pecłrinha que seu pai recolheu na beira de um rio, numa viagem, ao se lembrar de um passeio realizado em conjunto, pode ter o mesmo significado que ganhar um carrinho de controle remoto, referido a um hobby comu entre pai e fil ho. No entanto, o discurso capital ista recusa o engoob próprio dessa dialética da frustração, ludibriando os indivíduas de que o caminho de responder a demanda seria mais fácil e apaziguador, atribuindo valor ao segundo objeto, não pela importância que encontra dentro dessa relação específica, mas pelos atributos reais. Os pais, na tentativa de oferecer o "melhor" dojeto, se atrapal ham e se deixam capturar pela demanda social. As demandas insistentes e intermináveis das crianças vêm assinalar que não é do objeto real que se trata, o que se demanda é sempre o símbolo do amor, objeto de dom. Seria importante precisar que, para um objeto ser símbolo do amor, deve estar necessariamente relacionado à falta. Às vezes a maneira mais aplacadora do mal-estar da existência, angústia provocada pela falta, é o dom da palavra, muitas vezes veiculado na palavra não, que asseguraria para a criança que, mesmo que sua demanda não seja atendida, seu desejo é reconhecido, tendo como efeito um cessar da reivindicação, na qual o desejo pedia reconhecimento pela via da demanda.

atra leitura recorrente dos adultos a respeito das demandas incessantes das crianças, sublinhado sobretudo no discurso pedagógico, é de que está querendo "chamar a atenção" . No entanto, 
essa leitura, apesar de não parecer totalmente equivocada à primeira vista, é superficial porque remete sobretudo a uma suposta necessidade da criança de ser o centro das atençães e de ser satisfeita permanentemente. Nesse sentido, incorre no mesmo equívoco apontado anteriormente. A criança parece chamar, sim, a atenção do adulto, mas não é esatada. Os dojetos reais são oferecidos na tentativa de silenciar o incômodo derivado do desejo indestnutível, no entanto, não só fracassam nessa empreitada, como transformam as crianças em pequenas ditadoras e criaturas chatas. Observamos também uma outra possibilidade de leitura, a de que a reivindicação da atenção que a criança faz é o pedido direto pelo objeto de dom, sem desviar pelo dbjeto real. No entanto, pais e educadores, tomados pela lógica da satisfação pela via do dbjeto, muitas vezes não reconhecem o pedido de dom como um pedido legítimo. Dessa forma, o "só quer chamar a atenção" esvazia de sentido o apelo da criança, que mais uma vez não é escutada.

Retomando o caminho da constituição subjetiva, quanob se instala, entre a criança e a mãe, a dinâmica relativa ao estabelecimento do dom, a criança vive um tempo no qual tudo parece caminhar bem. Ela é bem sucedida em seu papel de objeto enganador do desejo da mãe e, nesse sentidb, a dialética da frustração parece dar conta da experiência com a mãe e o falo. Porém, em algum momento, essa pretensa harmonia se desestabiliza.

Do lado da criança, o encontro entre a pulsão real e o jogo imagi- 
nário do engodo produz a necessidade de uma nova organização. A pulsão que tem sua fonte no conpo, na organização fálica, conduz a criança à experiência de potência, porém, essa potência não é experimentada na relação com a mãe, para quem o "tudo" que a criança pode oferecer, é insuficiente. Por essa via, produz-se novamente um desencontro, necessário para desencadear a busca por uma nova organização.

O pequeno Hans se enrosca exatamente nesse momento. Ele vivia sua dialética da frustração com a mãe, que caminhava bem até se deparar com a emergência de seu pênis real e com o nascimento da irmã, cenas que o confrontam com sua situação de insuficiência em relação ao desejo da mãe. O pai real como agente da castração seria convocado nesse momento para solucionar o impasse, mas o pai de Hans não exerce essa função, o que o dbriga a inventar outros elementos para resolver este situação, o que faz ao preço de uma fobia.

A fobia se apresenta como uma das soluções imaginárias e provisórias para o sujeito que, diante da mãe insaciável, serve-se desta como medida de proteção. A autra saída imaginária possível é o fetichismo, instituindo um objeto no lugar da falta.

Ao armar uma fobia, o sujeito está interessado em manter o engodo do falo, ou seja, ele produz uma resposta à castração matema que, apesar de já ter sido vislumbrada, consiste na tentativa de manter a mãe completa, sem falta. A criança tenta permanecer como objeto de prazer para a mãe, oferece-se como o que Lacan denominou neste seminário, metonímia do falo.

o sujeito recua ou volta atrás diante da constatação da falta na mãe. A criança pressente que alguma coisa é desejada pela mãe, além dela mesma, Mas, tomada pelas marcas da volúpia do desejo materno, ainda se esforça por ser aquilo que, pela via significante, sacia essa mulher. Temos aqui a cristalização de um estado que deveria ser provisório, uma vez que a criança fóbica mantém sua função fálica e de estruturação metonímica em relação ao desejo de completude da mãe.

A idéía da fobia como placa giratória _ apresentada por Lacan no seminário De um outro ao Outro, de 1969 - introduz a formulação de que o estado fóbico, no tempo da constituição do sujeito, pode apresentar a consistência de um sintoma transitório, a ser desorganizado pelo movimento do desejo na própria criança, garantindo a estnuturação de uma neurose. Ou pode ainda recolocar ao sujeito a possibilidade de estabelecer um objeto fetiche _e não mais um significante, como fez na configuração da fobia _ no lugar daquilo que ele entende faltar à mãe, estruturando por essa via uma perversão.

A instalação do dojeto feticheé uma respasta bastante singular que a criança produz na direção da negação da castração matema. Por esse dojeto, símbolo do pênis da mulher, a criança restitui a mãe de sua perda, mantendo-a fálica e poderosa. Nesse sentido, o sujeito realiza uma operação de positivação do dbjeto, que garanta o reencontro com ele. Dessa maneira, instituindo um dbje- 
to para obturar a falta matema, o sujeito se protege da voracidade do desejo da mãe. Para elaborar uma resposta como essa, é preciso que a criança já tenha vislumbrado a falta materna e ao mesmo tempo não tenha encontrado um elemento significante que a regulamentasse simbolicamente. Dessa maneira, resolve o impasse em que se encontra dentro da tríade imaginária, negando a castração matema com a interposição do objeto fetiche, que tem a função de velar aquilo que o sujeito não pode admitir que a mãe não tem. O fetiche é uma resposta ao horror da castração, diante da qual cria-se um monumento, um substituto para ela.

Além dessas saídas imaginárias e sintomáticas que a criança inventa, na trama edípica, para lidar com a castração matema, há também uma saída simbólica. Essa ocorre quando a criança encontra no campo do outro um novo elemento para fazer frente a esse impasse. Esse elemento é o agente da função patema que, ao incidir sobre a relação da criança com a mãe, avança para o registro da falta nomeado como castração. Como veremos, para que o Édipo cumpra sua função normativa é preciso que ele faça sua conclusão na castração.

\section{CASTRAÇÃO}

É o pai real ${ }^{2}$ o agente que pode vir regular esse novo (des) encontro entre mãe, criança e falo, instituindo um quarto elemento para operar a castração matema e, assim, liberar a criança do desejo insaciável da mãe. Essa seria a saída pelo complexo de castração, terceiro registro possível da falta, que oferece uma estrutura simbólica por meio da operação da lei que regulamenta as trocas humanas: a interdição do incesto. Énesse ponto que a incompletude é legalizada, a transmissão da castração apazigua o sujeito, pois a falta ganha, definitivamente, estatuto de motor psíquico e não de vazio a ser preendridb.

A partir da incidência da operação simbólica da função patema, o falo, abjeto imaginário da dialética da frustração, é elevado ao estatuto de abjeto simbólico e pode, então, ser buscado tanto pelo menino como pela menina. Depois dessa qperação de castração, a criança sai marcada em relação ao falo, com um sinal de mais ou de menos. Afinal, numa dialética simbólica, "o que não se tem é tão existente quanto o resto" (Lacan, 195657, p. 125). Mas o que importa é que está marcada por ele e isso é o que vai vetorizar suas buscas pasteriores. O falo é a moeda principal que possibilitará as futuras trocas da criança com o outro.

É isso que Lacan (1956-57) formula no seguinte fragmento: "A partir desse momento de virada, o objeto não é mais o objeto imaginário com o qual um Outro é sempre capaz de mostrar que o sujeito não o tem, ou o tem de forma insuficiente. Se a castração exerce esse papel essencial para toda a continuação do desenvolvimento, é porque ela é necessária à assunção do falo materno como um objeto simbólico. Somente a partir do fato de 
que, na experiência edipiana essencial, ela está privada do abjeto por aquele que o tem, que sabe que 0 tem, que o tem em todas as ocasiões, é que a criança pode conceber que esse mesmo abjeto simbólico lhe será dado um dia" (p. 213) .

Assim, a saída neurótica do engodo da frustração é operada pela via da função patema: o pai real comparece como agente da introdução de uma falta simbólica de um dojeto imaginário: o falo. A castração vem dizer para o sujeito que seus dbjetos imaginários, apesar de estarem postos no lugar do que falta, não fazem completude. Nesse sentido, o atravessamento do Édipo desembocado na castração é uma saída simbólica e por isso mais estável. Esse é o momento crucial da estruturação do sujeito, uma vez que a castração reordena as relaçães do sujeito com a falta e dá um novo estatuto ao falo, que de dbjeto imaginário é alçado a condição simbólica: cono significante da falta, servindo de suporte para o jogo das infinitas substituições às quais o sujeito irá se submeter no decorrer de sua vida. Nesse sentido, se estabelece para a criança o que Lacan chamou de "jogo de quem perde, ganha" . A criança perde a ilusão da completude materna e ganha pertinência social, amplia seu circuito de trocas.

Para que o sujeito se constitua, é imprescindível a transmissão da falta. É próprio do humano que a satisfação não seja alcançada pelo encontro com o dbjeto, a satisfação pulsional é parcial e promovida pelo exercício do desejo, guardado pela manutenção da falta, que Lacan for- mulará mais tarde como o impossível da relação sexual.

A neurose como estrutura se arma aqui, como articulação do desejo insatisfeito, no caso da histeria, e impossível, na neurose dosessiva. Em ambos os casos, seu funcionamento e organização estão baseados na transmissão da falta como motor do desejo.

\section{REFERÊNCIAS BIBLIOGRÁFICAS}

Freud, S. (1895) . Projeto de uma psicologia. In: Coras isoladas de Freud. (Trad. Osmyr Faria Gabbi Jr.) Rio de Janeiro: Imago, 1995.

Lacan, J. (1956-57) . O seminário - Iivro 4: a relação de objeto. Texto estabelecido por Jacques AlainMiller. Rio de Janeiro: Jorge Zahar, 1995.

. (1964) . O seminário - livro 11: as quatro conceitos fundamentais da psicanálise. Texto estabelecido por Jacques Alain Miller. Rio de Janeiro: Jorge Zahar, 1985.

NOTAS

1 Terminologia sugerida por Osmir Faria Gabbi Jr. (1995) , em sua tradução comentada do texto do Projeto.

2 É importante ressaltar que tal operação não é realizada pelo pai simbólico que, neste seminário, é definido por Lacan nos termos de uma construção mítica.

Recebido em jumho/2004. Aceito emagasto/2004. 